\title{
A comparison of several modern alkylating agents
}

\author{
Guy Lamoureux* and Christian Agüero \\ Escuela de Química and Centro de Investigaciones en Productos Naturales \\ Universidad de Costa Rica, 2060 San Pedro, San José, Costa Rica \\ E-mail: glamoure@cariari.ucr.ac.cr
}

\begin{abstract}
This review covers the application, mechanisms and limitations of simple alkylating agents that can be used for the conversion of carboxylic acids to esters, phenols to aryl ethers, enols to enol ethers and thiols to thioethers. Specific recent examples are provided to show the selectivity (regio or chemo) in these transformations. It is important to have access to these methods when considering alternatives to classical alkylating techniques.
\end{abstract}

Keywords: Alkylation, diazomethane, esters, aryl ethers, enol ethers, thioethers

\section{Table of Contents}

1. Introduction

2. Classification of Alkylating Agents

3. Alkylating Agents used in Basic Conditions

3.1 Alkyl halides

3.2 Sulfonate esters

3.3 Oxonium salts

3.4 Dimethyl sulfate

3.5 Dimethyl carbonate

3.6 Tetramethylammonium salts

4. Alkylating Agents used in Neutral Conditions

4.1 Diazomethane

4.2 Trimethylsilyldiazomethane

4.3 Aromatic triazenes

4.4 Dialkyl acetals of $N, N$-dimethylformamide

4.5 O-Methylcaprolactam

4.6 Isourea ethers

4.7 Orthoesters 
4.8 Alkoxy- $\lambda^{6}$-sulfanenitriles (thiazynes)

4.9 $S$-Propargyl xanthates

5. Conclusions

\section{Introduction}

The alkylation of various acidic functional groups (Scheme 1) is important in total synthesis, to form derivatives, and in the preparation of protecting groups. ${ }^{1}$ There have been many procedures to alkylate these groups using "classic" reagents (where R'Z are small alkyl electrophiles) ${ }^{2}$ but recently the search for new and improved alkylating agents has provided several alternatives to these traditional routes. In this review, we will discuss the classification of these reagents based on mechanistic considerations and how each compound has its advantages and limitations.

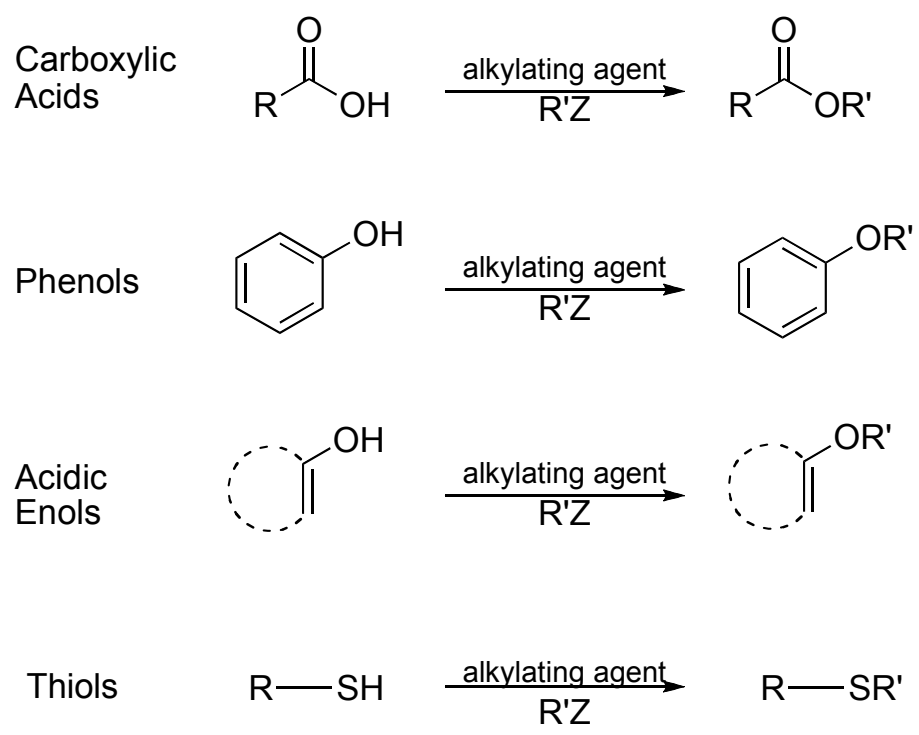

Scheme 1. Alkylation of acidic functional groups.

\section{Classification of Alkylating Agents}

One can separate different alkylating agents into 3 categories which depend on the conditions of the reaction: basic, neutral or acidic (Table 1). Associated with each condition is the mechanistic analysis which provides an idea of how the reaction takes place. For instance, if the alkylating agent is an electrophile in basic conditions, the mechanism shown in the first line in Scheme 2 is assumed to take place for a carboxylic acid. If the reaction takes place in neutral conditions, there are different mechanistic possibilities where the reagent acts as a base first, forming an activated 
species which readily continues the alkylation. Finally, in the case of acidic conditions (Brønsted or Lewis), the alkylating agent generally behaves as a nucleophile.

Table 1. Examples of alkylating agents

\begin{tabular}{ccc}
\hline Basic Conditions & Neutral Conditions & Acidic Conditions \\
\hline Me-I & Diazomethane: $\mathrm{CH}_{2} \mathrm{~N}_{2}$ & $\mathrm{MeOH} / \mathrm{H}^{+}$ \\
$\mathrm{Me}-\mathrm{OTs}, \mathrm{Me}-\mathrm{OMs}$ & $\mathrm{TMSCHN}$ & $\mathrm{MeOH} / \mathrm{BF}_{3}$ \\
$\mathrm{Me}_{3} \mathrm{O} \cdot \mathrm{BF}_{4}$ & Triazene: $\mathrm{Ph}-\mathrm{NH}-\mathrm{N}=\mathrm{NMe}$ & \\
$\mathrm{Me}_{2} \mathrm{SO}_{4}$ & DMF Acetal: $(\mathrm{MeO})_{2} \mathrm{CHNMe}$ & \\
$\mathrm{MeOCO}_{2} \mathrm{Me}$ & Isourea: $\mathrm{RNHC}(\mathrm{OMe}) \mathrm{NR}$ & \\
$\mathrm{Me}_{4} \mathrm{NX}$ & Orthoacetal: $(\mathrm{MeO})_{3} \mathrm{CR}$ & \\
\hline
\end{tabular}

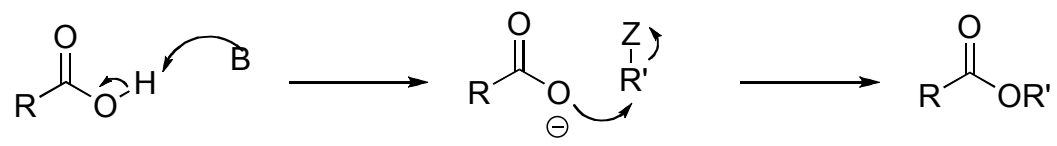

Neutral Conditions (reagent acts first as base)<smiles>[R]CCCOC([R])=O</smiles><smiles>[V]C1CCCCC1</smiles><smiles></smiles><smiles>[13CH3]</smiles><smiles>[R]OC([R])=O</smiles>
OR<smiles>[R]C(=O)OCCI</smiles>

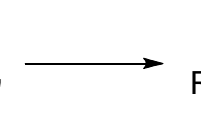<smiles>[R]C(=O)OC[Te][Z]([H])([H])C</smiles>

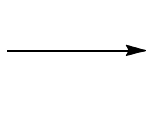<smiles>[R]OC([R])=O</smiles>

Acidic Conditions (reagent acts as nucleophile)
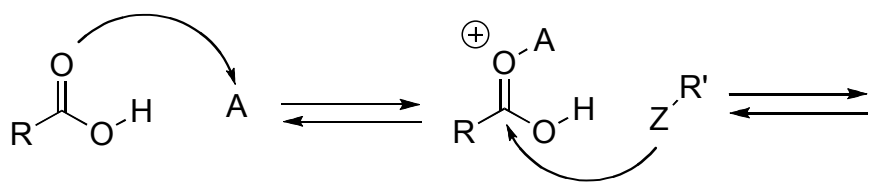

Scheme 2. Mechanistic aspects of alkylation of a general carboxylic acid.

The discussion of reactions where the alkylating agent is activated by other compounds (such as the Mitsunobu reaction) ${ }^{3}$ or the external activation of the acidic compound (such as DDC) ${ }^{4}$ will not be included in this review. The alkylation of carboxylic acids with alcohols in acidic conditions, commonly known as Fischer Esterification, has been reviewed in detail ${ }^{5}$ and also will not be discussed here. This reaction has its limitations: small functional groups are required to reduce steric interactions and, because it is reversible, the equilibrium constant is not favorable. More interesting and effective is the use of basic, or preferably neutral, conditions. These latter transformations usually are more selective and occur under milder conditions than the acidic 
alkylations. The reaction is usually irreversible and can provides high yields of products. Furthermore, these reagents are not reserved only for carboxylic acids but to the alkylation of any acidic functional group.

\section{Alkylating Agents used in Basic Conditions}

The classic reagents for the alkylation under basic conditions are alkyl iodides or the corresponding mesylates or tosylates. For instance, the Kuhn methylation ${ }^{6}$ uses $\mathrm{MeI}$ and $\operatorname{Ag}_{2} \mathrm{O}$ for the alkylation of natural products. Instead of the sulfonate esters (MeOMs, MeOTs), ${ }^{7}$ a modern alternative is to use polymer-bound methyl sulfonate, ${ }^{8}$ which is easily handled, allows simple work-up and is recyclable (Scheme 3). Other acidic functional groups are also smoothly alkylated.<smiles>COC(=O)c1c(C)cc(C)cc1CN(C)C(=O)Oc1ccc(OC)cc1</smiles>

Scheme 3. Use of polymer-bound sulfonate ester.

In aqueous conditions, it is possible to use Meerwein methylation, ${ }^{9}$ using the corresponding oxonium salts $\left(\mathrm{Me}_{3} \mathrm{O} \cdot \mathrm{BF}_{4}\right)$ with $\mathrm{NaHCO}_{3}$. However, these salts are rapidly hydrolyzed in water. ${ }^{10} \mathrm{~A}$ better procedure with these reagents is to use dichloromethane as solvent and a bulky amine as base. ${ }^{11}$ Under these conditions, even sterically hindered or sensitive acids can be alkylated (Scheme 4). However, the alkylation is limited to the methyl and ethyl esters, from the corresponding oxonium salts which are most easily available.<smiles>CC(=O)Oc1ccccc1C(=O)O</smiles><smiles>CO[14CH3]</smiles><smiles>CCCCCCCCCNCC</smiles><smiles>COC(=O)c1ccccc1OC(C)=O</smiles>

Scheme 4. Methylation using Meerwein salts.

Similar in scope is the Haworth methylation (dimethyl sulfate with aqueous $\mathrm{NaOH}^{12}$ or an amine $^{13}$ ). In a variation of the classic Haworth methylation, a recent development uses dimethyl sulfate and $\mathrm{LiOH}$ in THF as the solvent. ${ }^{14}$ This procedure reduces the possible side reactions and provides almost quantitative yields, even with hindered acids (Scheme 5). The chemoselectivity of these conditions is shown in the case of phenolic acids; only the carboxylic acid reacts (Scheme 5). 

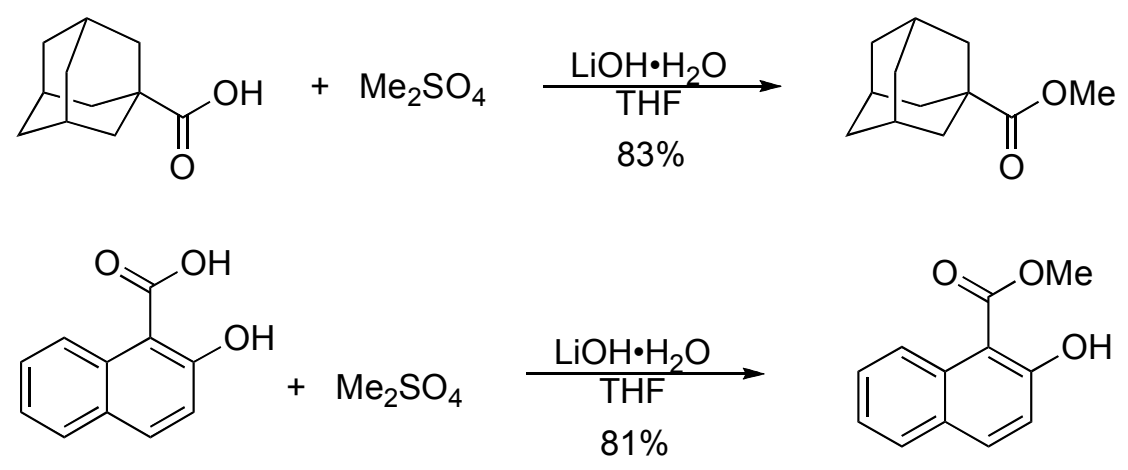

Scheme 5. Dimethyl sulfate as alkylating agent.

It should be noted that the use of the "classic" electrophilic reagents comes with a high risk of toxicity. ${ }^{15}$ Methyl iodide (and other alkyl halides) are known carcinogens. ${ }^{16}$ Dimethyl sulfate as an alkylating agent is especially dangerous since this reagent is an extremely hazardous liquid and vapor (causes delayed burns to lungs and tissues, may be fatal if inhaled). Dimethyl carbonate has been shown to be a safe (and environmentally friendly) replacement for these reagents. ${ }^{17}$ In the presence of $\mathrm{K}_{2} \mathrm{CO}_{3}$ or $\mathrm{DBU}^{18}$ it is especially reactive. The reagent also alkylates phenols ${ }^{19}$ but can be chemoselective for acids in the presence of NaY Faujasite (Scheme 6). ${ }^{20}$

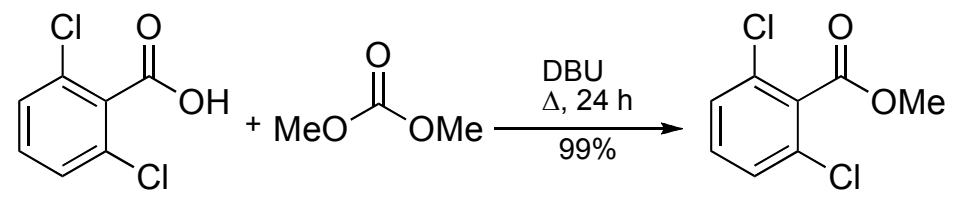

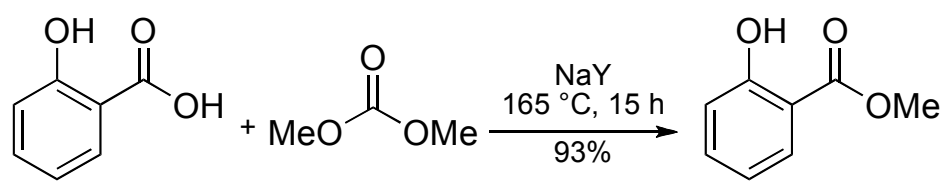

Scheme 6. Alkylations with dimethyl carbonate.

Tetramethylammonium salts are other replacement alkylating agents which are non-volatile and non-carcinogenic. However, due to their lower reactivity, high temperatures (such as the injection port during a gas chromatographic analysis) are required. ${ }^{21}$ For the alkylation of phenols, microwave conditions have been used with success. ${ }^{22}$ The reaction is chemoselective for the phenolic hydroxyl group over the alcohol (Scheme 7). 


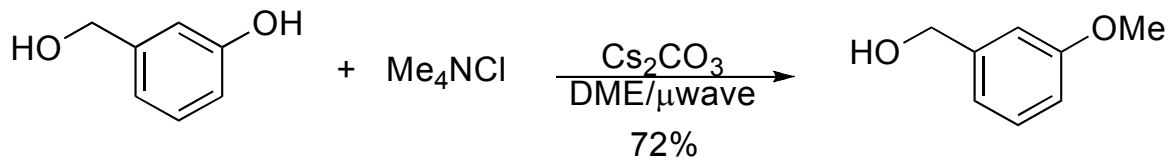

Scheme 7. Chemoselective alkylation using tetramethylammonium chloride.

\section{Alkylating Agents used in Neutral Conditions}

The methylation of carboxylic acids and other acidic functional groups is often carried out in neutral conditions using diazomethane $\left(\mathrm{CH}_{2} \mathrm{~N}_{2}\right) \cdot{ }^{23}$ However, due to its toxicity and the explosive nature of diazomethane (as well as the danger in the preparation and the carcinogenicity of the commercially available precursors), ${ }^{24}$ several alternative reagents recently have been developed. Trimethylsilyldiazomethane (TMSD) has been touted as a stable and safe alternative to diazomethane, ${ }^{25}$ but its use is constrained by its high cost and lower efficiency. There are differences between the alkylations using these diazo compounds. Scheme 8 shows the corresponding mechanisms and indicates the importance of the addition of methanol in the case of TMSD. Reactions with higher alkyl diazo compounds are not common, due to limited access to the synthesis of these substituted diazo reagents. However, an in situ procedure for the formation of phenyldiazomethane (which forms benzyl derivatives) has been published. ${ }^{26}$

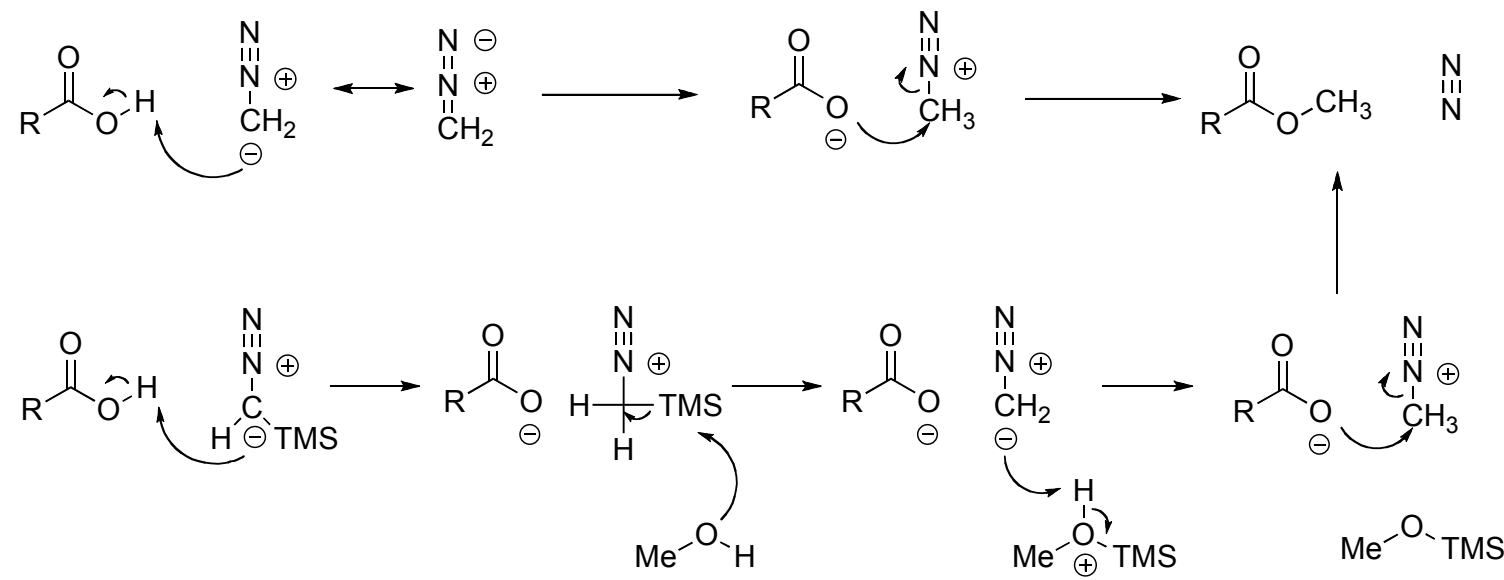

Scheme 8. Comparison of diazomethane and trimethylsilyldiazomethane.

The aromatic triazenes, especially of $p$-toluidine (Scheme 9), can be used as alkylating agents of carboxylic acids ${ }^{27}$ and vinylogous acids. ${ }^{28}$ However, these reagents are also carcinogenic ${ }^{29}$ and have the risk of being explosive. ${ }^{30}$ Recently, polymer-bound triazenes have been shown to be "smart" reagents for alkylations. ${ }^{31}$ 
<smiles>COC(=O)c1cc([N+](=O)[O-])cc([N+](=O)[O-])c1</smiles>

Scheme 9. p-Toluidine triazene methylation.

The mechanism of this transformation reveals this reagent to be a type of vinylog of diazomethane (Scheme 10). The only products which remain after decomposition of the reagent (nitrogen gas and $p$-toluidine) are easily removed or recycled.<smiles>[R]C(=O)O[C+]1CCCCN([Z7])N=NNC1</smiles><smiles>N=[NH+]N[Po]</smiles>
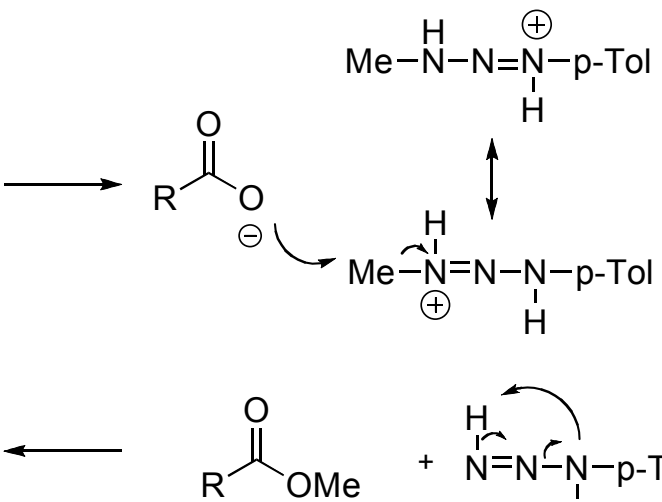<smiles>[R]C(=O)OC</smiles>

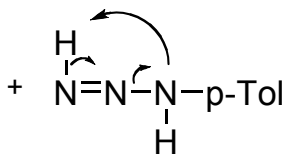

Scheme 10. Mechanism for alkylation of carboxylic acids using triazenes.

Dialkyl acetals of $N, N$-dimethylformamide (DMF) are often useful alkylating agents under neutral conditions. The methyl, ethyl and even the $t$-butyl derivatives are the most commonly used to form the corresponding esters (Scheme 11). ${ }^{32}$ Heterocycles with $\mathrm{SH}, \mathrm{NH}$ and $\mathrm{OH}$ can also be methylated with DMF dimethyl acetal (Scheme 11). ${ }^{33}$

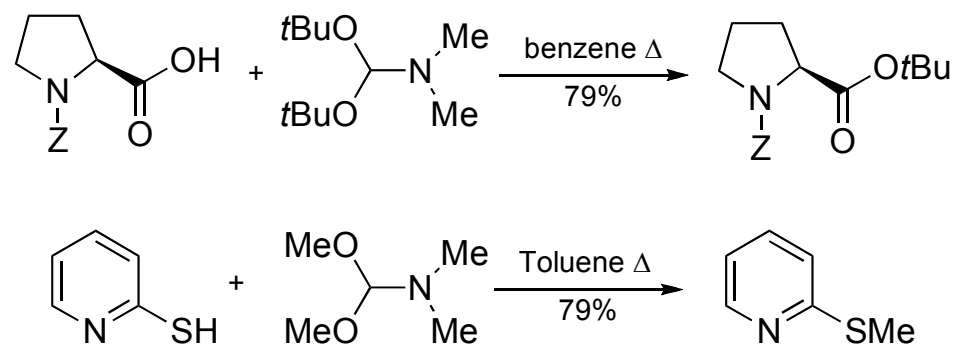

Scheme 11. Alkylations with acetals of DMF. 
Phenols can also be readily alkylated under neutral conditions. An example is the formation of $t$-butyl ethers of derivatives of morphine, which can readily decompose under acidic conditions (Scheme 12). ${ }^{34}$

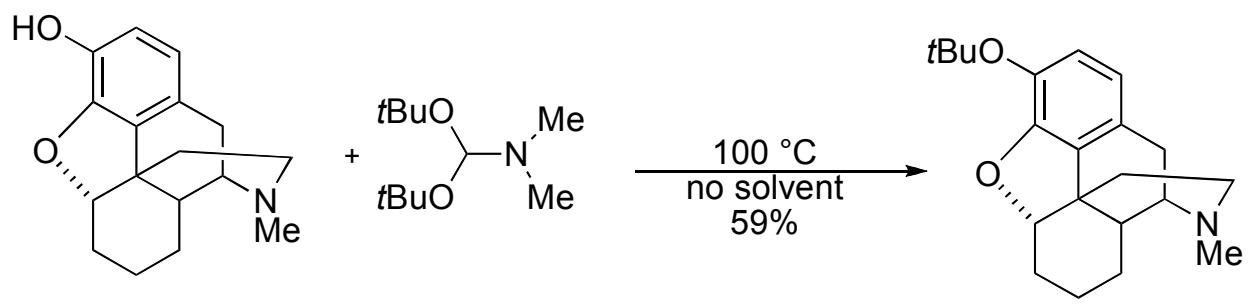

Scheme 12. Neutral conditions to form aryl t-butyl ethers.

Related to the DMF acetals are the corresponding lactim ethers of cyclic amides. For example, $O$-methylcaprolactam has been shown to alkylate carboxylic acids at high temperatures (Scheme 13). ${ }^{35}$<smiles>COC(=O)c1ccccc1</smiles>

Scheme 13. Lactim ethers as alkylating agents.

A variety of esters can be prepared, even in the presence of various functional groups, with isourea ethers ${ }^{36}$ (Scheme 14). ${ }^{37}$ These compounds are easily formed from the corresponding alcohol and dicyclohexylcarbodiimide (DCC) or diisopropylcarbodiimide (DIC), which provides great flexibility to use methyl, $1^{\circ}, 2^{\circ}$ or $3^{\circ}$ alkylating groups. ${ }^{38}$ The polymer-supported $O$-methyl isourea has been developed for the efficient methylation of acids. ${ }^{39}$

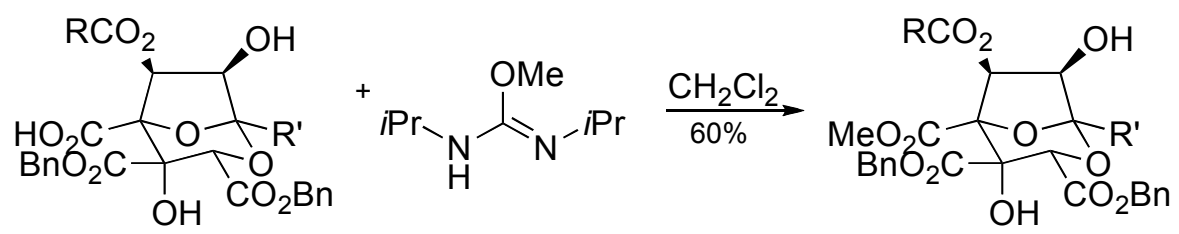

Scheme 14. $O$-Methyl isourea for mild alkylations.

An interesting showcase of the reactivity of these reagents is the regioselectivity in the case of enols. Only the 4-O-alkylated product (as expected for such "hard" alkylating agents) is obtained from tetronic acid derivatives (Scheme 15); no C-alkylation was observed. ${ }^{40}$ 


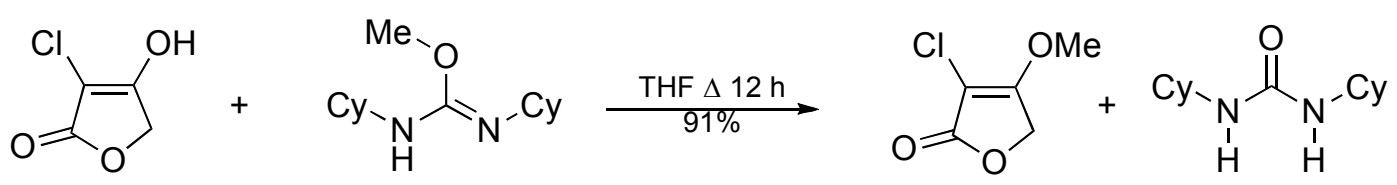

Scheme 15. Regioselective O-alkylation of enols.

The mechanisms of the three "amide-based" alkylations are related; they all proceed via a protonated intermediate that activates the electrophile to attack by the nucleophile which provides an amide as the stable product (Scheme 16). The fact that primary, secondary and even tertiary groups react shows that the displacement step can have $\mathrm{S}_{\mathrm{N}} 1$ or $\mathrm{S}_{\mathrm{N}} 2$ character. ${ }^{41}$
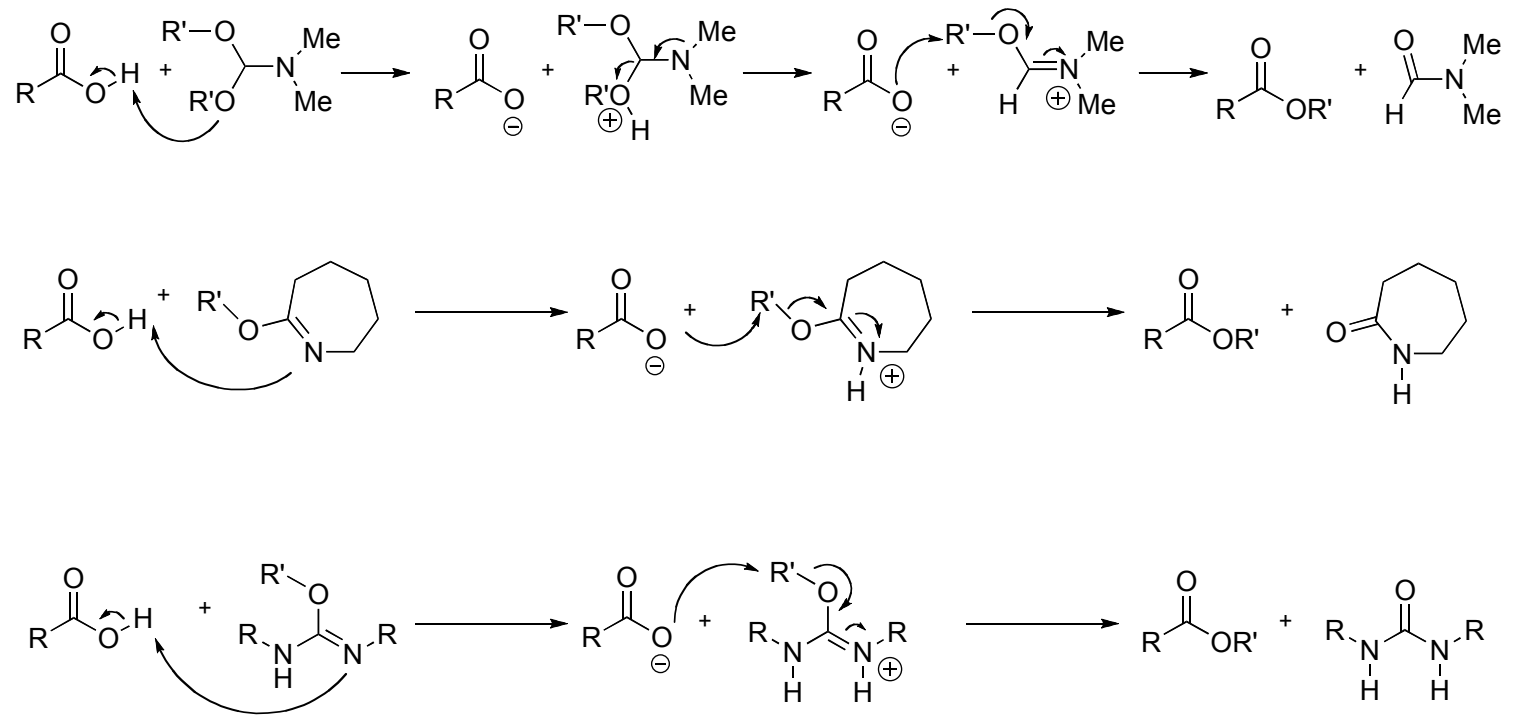

Scheme 16. Comparison of the mechanisms of "amide-based" alkylations.

Orthoesters can be used for the alkylation of acids, including amino acids. ${ }^{42}$ There is evidence that the orthoesters of acetic acid react more effectively than those of formic acid for carboxylic and sulfonic acids. ${ }^{43}$ The reaction is mild enough to chemoselectively form the ester in the presence of other functional groups (Scheme 17). ${ }^{44}$ The reaction can also be run efficiently in room temperature ionic liquids as solvents. ${ }^{45}$

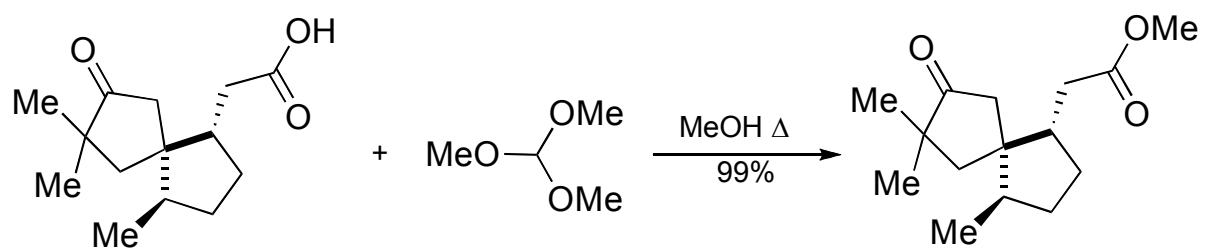

Scheme 17. Formation of methyl esters using orthoesters. 
This transformation depends on the formation of an oxonium intermediate during the process (Scheme 18). The presence of this intermediate (and helping rule out a direct nucleophilic mechanism) is suggested by the fact that steric effects are not important and that acetic orthoesters can better stabilize the cationic intermediate by induction, hence a more rapid reaction.

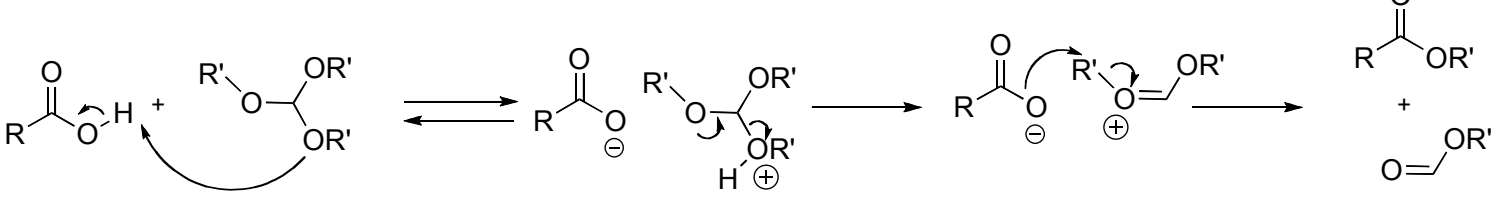

Scheme 18. Mechanism of alkylation using orthoesters.

Recently, the surprising chemistry of alkoxy- $\lambda^{6}$-sulfanenitriles (thiazynes) has been investigated and these compounds have been found to alkylate carboxylic acids, thiols, phenols and sulfonic acids in essentially quantitative yields at room temperature (Scheme 19). ${ }^{46}$

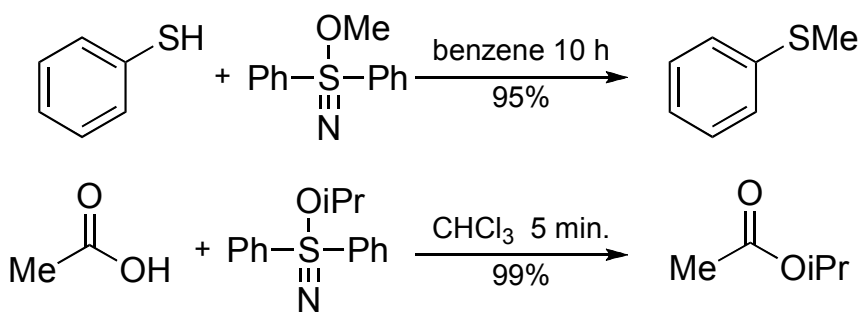

Scheme 19. Use of thiazynes as alkylating agents.

The displacement of the alkyl group is opposite to that expected by a $\mathrm{S}_{\mathrm{N}} 2$ mechanism-i.e. isopropyl groups react faster than methyl groups. This fact indicates that the reaction must have at least some $\mathrm{S}_{\mathrm{N}} 1$ character.

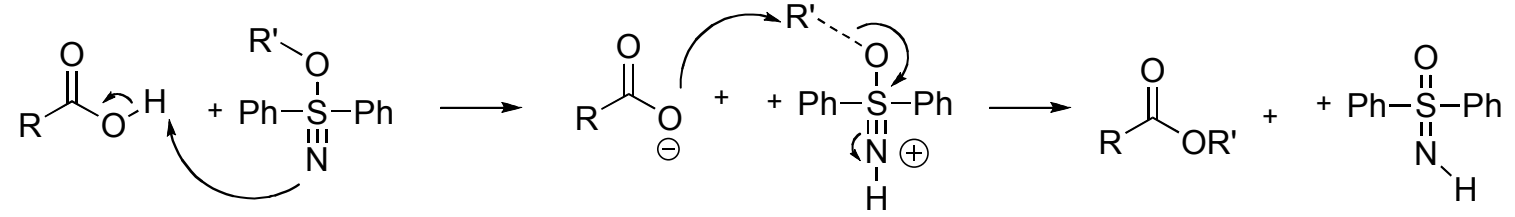

Scheme 20. Alkylation mechanism of thiazynes.

$S$-propargyl xanthates have been used for the esterification of acids (Scheme 21). ${ }^{47}$ This method shows high reactivity (even for the synthesis of neopentyl esters, which are notoriously difficult to form) and complete inversion of stereochemistry for secondary alcohols. 


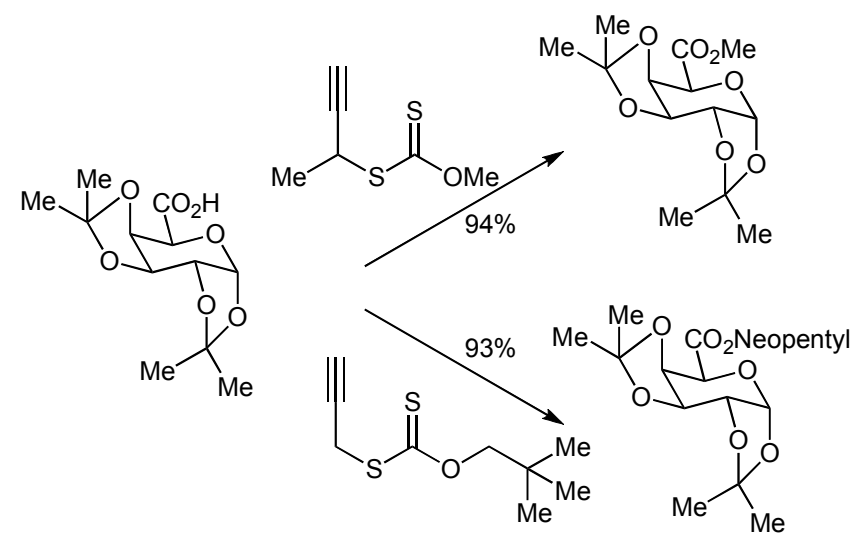

Scheme 21. Examples of alkylations using xanthates.

The mechanism proposed for this transformation involves a sigmatropic rearrangement followed by formation of a betaine intermediate. This structure deprotonates the acidic proton and allows displacement by the nucleophile in a $\mathrm{S}_{\mathrm{N}} 2$ process (Scheme 22).

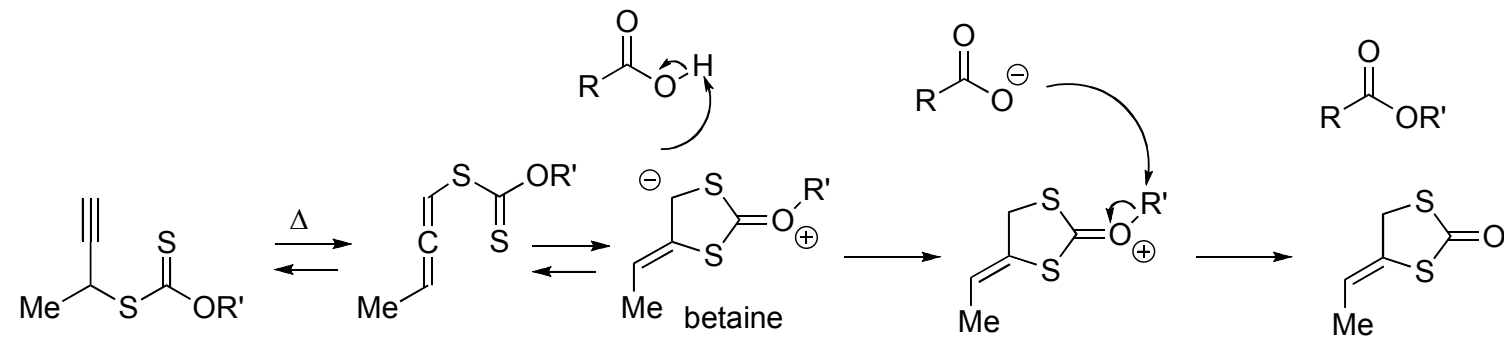

Scheme 22. Proposed mechanism of xanthate alkylation.

\section{Conclusions}

It is important to reevaluate the alkylating groups that we use in the laboratory, to reflect on the selectivity or toxicity of the reagents and not only to select the most common ones. Today, the importance of Green Chemistry requires that we consider the atom efficiency as well as the danger to the environment of the chemicals. Using these criteria, the most efficient alkylating agents appear to be the isoureas and the dialkyl carbonates. These reagents are easily and cheaply available, can contain a variety of functional groups and are remarkably selective. The dialkyl carbonates are slightly more atom efficient but the urea product formed in the alkylation using isoureas can be easily separated and recycled.

In summary, in an alkylation reaction during a synthesis one must decide on the relevant conditions, type of selectivity and the efficiency of the process before selecting the right reagent. We hope that this review will make the final decision easier to make. 


\section{Acknowledgements}

We wish to thank the Vicerrectoria de Investigación, Escuela de Química and Centro de Investigaciones en Productos Naturales at the Universidad de Costa Rica for their support.

\section{References}

1. Furniss B. S.; Hannaford A. J.; Smith P. W. G.; Tatchell, A. R. Vogel's Textbook of Practical Organic Chemistry, 5th Edn.; Wiley: New York, 1989.

2. Paquette, L. A. Encyclopedia of Reagents for Organic Synthesis; Wiley: New York, 1995, Vol. 3, 5105.

3. Mitsunobu, O. Synthesis 1981, 1.

4. Gorecka, A.; Leplawy, M.; Zabrocki, J.; Zwierzak, A. Synthesis, 1978, 475.

5. Otera, J. Esterification: Methods, Reactions and Applications VCH: Weinheim, 2003.

6. Kuhn, R. Angew. Chem. Int. Ed. Eng. 1962, 1, 19.

7. Ogura, F.; Yamaguchi, H.; Otsubo, T.; Nakano, T.; Saito, T. Bull. Chem. Soc. Jpn. 1983, 56, 1257.

8. Yoshino, T.; Togo, H. SynLett 2005, 517.

9. Meerwein, H.; Borner, P.; Fuchs, O.; Sasse, H. J.; Schrodt, H.; Spille, J. Chem. Ber. 1956, 89, 2060. Meerwein, H.; Hinz, G.; P. Hofmann, P.; Kroning, E.; Pfeil, E. J. Prakt. Chem. 1937, 147, 257.

10. Hamada, T.; Yonemitsu, O. Chem. Pharm. Bull. 1971, 19, 1444.

11. Raber, D. J.; Gariano, P.; Brod, A. O.; Gariano, A.; Guida, W. C.; Guida, A. R.; Herbst, M. D. J. Org. Chem. 1979, 44, 1149.

12. Haworth, W. N. J. Chem. Soc. 1915, 8.

13. (a) Stodola, F. H. J. Org. Chem., 1964, 29, 2490. (b) Grundy, J.; James, B. G.; Pattenden, G. Tetrahedron Lett. 1972, 757.

14. Chakraborti, A. K.; Basak, A.; Grover, V. J. Org. Chem. 1999, 64, 8014.

15. Bolt, H. M.; Gansewendt, B. Crit. Rev. Toxicol. 1993, 23, 237-253.

16. (a) Pokier, L. A.; Stoner, G. D.; Shimkin, M. B. Cancer Res. 1975, 35, 1411. (b) Mc Cann, J.; Choi, E.; Yamasaki, E.; Ames, B. N. Proc. Nati. Acad. Sci. U.S.A. 1975, 72, 5135.

17. Memoli S, Selva M, Tundo P. Chemosphere 2001, 43, 115. (b) Tundo, P.; Selva, M. Acc. Chem. Res. 2002, 35, 706-716.

18. Shieh, W.-C.; Dell, S.; Repic, O. J. Org. Chem. 2002, 67, 2188.

19. (a) Shieh, W.-C.; Dell, S.; Repic, O. Org. Lett. 2001, 3, 4279. (b) Ouk, S.; Thiébaud, S.; Borredon, E.; Le Gars, P. Green Chem. 2002, 4, 431. (c) Shen, Z. L.; Jiang, X. Z.; Mo, W. M.; Hu, B. X.; Sun, N. Green Chem. 2005, 7, 97. (d) Rajabi, F.; Saidi, M. R. Synth. Commun. 2004, 34, 4179.

20. Selva, M.; Tundo, P. J. Org. Chem. 2006, 71, 1464. 
21. Wells, R. J. J. Chromatogr., A 1999, 843, 1.

22. Maras, N.; Polanc, S.; Kocevar, M. Tetrahedron 2008, 64, 11618.

23. Black, T.H. Aldrichimica Acta 1983, 16(1), 3.

24. Proctor, L. D.; Warr, A. J. Org. Process Res. Dev. 2002, 6, 884.

25. Hodnett, N. S. SynLett 2003, 2095.

26. Aggarwal, V. K.; Alonso, E.; Bae, I.; Hynd, G.; Lydon, K. M.; Palmer, M. J.; Patel, M.; Porcelloni, M.; Richardson, J.; Stenson, R. A.; Studley, J. R.; Vasse, J.-L.; Winn, C. L. J. Am. Chem. Soc. 2003, 125, 10926.

27. (a) White, E. H.; Baum, A. A.; Eitel, D. E. Org. Synthesis Coll. Vol. 5, Wiley: New York, 1973; p 797. (b) ibid. Vol. 48, 1968, p102.

28. Duplantier, A. J.; Andresen, C. J.; Cheng, J. B.; Cohan, V. L.; Decker, C.; DiCapua, F. M.; Kraus, K. G.; Johnson, K. L.; Turner, C. R.; UmLand, J. P.; Watson, J. W.; Wester, R. T.; Williams, A. S.; Williams, J. A. J. Med. Chem. 1998, 41, 2268.

29. Preussmann,R.; Druckrey, H.; Irankovic, S.; Hodenberg, A. Ann. N.Y. Acad. Sci. 1969, 163, 697.

30. White, E. H.; Scherrer, H. Tetrahedron Lett. 1961, 758.

31. (a) Pilot, C.; Dahmen, S.; Lauterwasser, F.; Bräse S. Tetrahedron Lett. 2001, 42, 9179. (b) Rademann, J.; Smerdka, J.; Jung, G.; Grosche, P.; Schmid, D. Angew. Chem., Int. Ed. Eng. 2001, 40, 381. (c) Erb, B.; Kucma, J.-P.; Mourey, S.; Struber, F. Chem. Eur. J. 2003, 9, 2582.

32. Widmer, U. Synthesis 1983, 135.

33. Stanovnik, B.; Tisler, M.; Hribar, A.; Barlin, G. B.; Brown, D. J. Aust. J. Chem. 1981, 34, 1729.

34. Mohacsi, E.; Leimgruber, W.; Baruth, H. J. J. Med. Chem. 1982, 25, 1264.

35. Mohacsi, E. Synth. Commun. 1982, 12, 453.

36. Liu, Y. SynLett 2009, 8, 1353.

37. Biftu, T.; Acton, J. J.; Berger, G. D.; Bergstrom, J. D.; Dufresne, C.; Kurtz, M. M.; Marquis, R. W.; Parsons, W. H.; Rew, D. R.; Wilson, K. E. J. Med. Chem. 1994, 37, 421.

38. Mathias, L. J. Synthesis 1979, 561.

39. Crosignani, S.; White, P. D.; Linclau, B. J. Org. Chem. 2004, 69, 5897.

40. Schobert, R.; Siegfried, S. SynLett 2000, 5, 686.

41. Jaeger, R. J. Phys. Org. Chem. 1998, 11, 47.

42. Pastó, M.; Castejón, P. Moyano, A.; Pericás, M. A.; Riera, A. J. Org. Chem. 1996, 61, 6033.

43. Trujillo, J. I.; Gopalan, A. S. Tetrahedron Lett. 1993, 34, 7355.

44. Crimmins, M. T.; DeLoach, J. A. J. Am. Chem. Soc. 1986, 108, 800.

45. Yoshino, T.; Togo, H. Synlett 2004, 1604.

46. Hao, W.; Fujii, T.; Dong, T.; Wakai, Y.; Yoshimura, T. Heteroatom Chem. 2004, 15, 193.

47. Boivin, J.; Henriet, E.; Zard, S. Z. J. Am. Chem. Soc. 1994, 116, 9739. 


\section{Author's biographies}

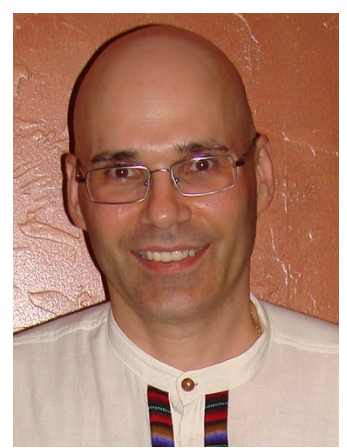

Guy V. Lamoureux was born in Canada y graduated with his Ph.D. in 1992 with Prof. G. Whitesides at Harvard University. He is currently a professor at the Universidad de Costa Rica (UCR) and the Centro de Investigación de Productos Naturales (CIPRONA) in Costa Rica studying the synthesis and properties of natural products.

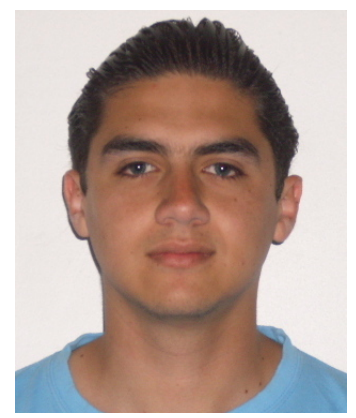

Christian Agüero was born in Japan in 1981 and grew up in Costa Rica where he received his bachelor's degree in Chemistry Science from Universidad de Costa Rica (UCR) in 2005. He is currently pursuing a "Licenciatura" in Chemistry at UCR and is working as a research assistant on the synthesis and activity of derivatives of naphthoquinones at CIPRONA (Centro de Investigación en Productos Naturales). 